\title{
Do Not Close My School: Facebook, Occupations and Demonstrations for Promoting Social Change
}

\author{
Fernando Rezende da Cunha Júnior ${ }^{1, *}$, Monica Ferreira Lemos ${ }^{2}$ \\ ${ }^{1}$ Department of Research and Theory in Education, Faculty of Behavioural and Movement Sciences, Vrije Universiteit Amsterdam, \\ Amsterdam, The Netherlands \\ ${ }^{2}$ Institute of Behavioural Sciences, Centre for Research on Activity, Development and Learning, University of Helsinki, Helsinki, Finland
}

Email address:

f.rezendedacunhajunior@vu.nl (F. R.da C. Júnior), lemos@helsinki.fi (M. F. Lemos)

${ }^{*}$ Corresponding author

To cite this article:

Fernando Rezende da Cunha Júnior, Monica Ferreira Lemos. Do Not Close My School: Facebook, Occupations and Demonstrations for Promoting Social Change. Humanities and Social Sciences. Vol. 5, No. 6, 2017, pp. 222-229. doi: 10.11648/j.hss.20170506.15

Received: October 17, 2017; Accepted: November 10, 2017; Published: December 15, 2017

\begin{abstract}
This article describes how secondary education students from the state of São Paulo, Brazil, protested against the closure of ninety-four schools of public educational system. The movement named 'Do not close my school' was a combination of online protest, using Facebook pages, occupy-type protest, in which students occupied more than 200 schools, and demonstrations, which occurred in different cities of the state. It was a movement organized by the students, with no official support of school managers, and lasted more than two months. We analyse the activities involved in the 'Do not close my school' movement under a Cultural-Historical Activity Theory framework, and we discuss how the concept of collaborative agency is important for the development of such a protest. As data, we use the content of pages on Facebook from fifty-six groups related to the school occupation and 111 official pages, also on Facebook, from the schools. We performed a multimodal and network analysis of the data in order to understand how the movement developed which results were obtained by the students. Our findings suggest that by acting collaboratively students were able to reach satisfactory results from their protests. In addition, they expanded the activities in their groups on Facebook to other contexts, like organizing events in their schools or using them for other social movements.
\end{abstract}

Keywords: Occupation, Online Communication, Collaborative Agency, Students’ Movement

\section{Introduction}

The last decade demonstrated that internet has caused changes in the field of communication and social movements [1], [2], [3], [4]. With the advent of Social Networking Sites (SNS) such as Facebook and Tweeter, communicating, sharing information and mobilizing people [5], [6] has become a means to redefine public spaces [7]. The communicative processes inside SNS can also play the role of a mediational tool for collective activism [8] and for enabling different opportunities for collective activities [9].

That influence of internet could be observed in some protests around the world. Some protests such as the Five Star Movement, occurred in Italy in 2009 [10], the protests in New York, Madrid, London, in 2011, as well as in other cities [11], and more recently the demonstrations against corruption in Brazil, are good examples of how social movements mobilize their participants online [12]. In those examples, the participants first mobilized the participants online, and then went to the streets [13]. They could be invited either by the organizers of the movement or by other people who had already been invited to participate in the movement.

We also have examples of how people start to protest on the streets and go to online environments, such as some occupy-type protests, which also enables the participants to reflect on their collective actions [4], [14], and to collaborate physically and online in order to reach their objectives [15], [16]. The occupy-type protests also enhance the connectivity among people [17]. In addition, they can be seen as an attempt of de-legitimizing existing policies, leading administrators to change [18], which also contributes to a shift in the balance of power amongst traditional actors [19], [20]. Thus, occupy-type movement has both online and 
offline networks, and social media plays a crucial role [21] for communication and development of such activities. By being connected, the individuals have the possibility of becoming a political agent in their communities, employing 'information and communication technologies to socially connect within networked publics' [22].

Therefore, this article describes an exploratory study on how secondary education students from the public educational system of São Paulo, Brazil, protested against the closure of ninety-four schools from the State Educational System. To do so, students organized a movement named 'Do not close my school', which was a combination of occupy-type protest [14], [23], online protests and demonstrations on the streets. The movement started in one school in the outskirts of the city of São Paulo, after the state government had announced a reorganization plan for the educational system.

In that moment, students occupied the school, and created a Facebook fan page for the movement, where they could post updates about their situation. That movement spread to other schools in the state, and one month after the beginning of the movement there were more than two hundred schools occupied by students in different cities of the state of São Paulo and fifty-six fan pages on Facebook related to the movement 'Do not close my school'. In the meantime, students also organized demonstrations in important avenues in different cities in the State of São Paulo.

As data, we use the posts from those fifty-six fan pages on Facebook related to the movement, and official pages from schools. We analyse the data from a mix-method perspective in order to provide an overview of the movement, combining multimodal and network analysis. In the following sections we present the theoretical background, the context of the movement 'Do not close my school', and the methodology used in this study. Finally, we present the results obtained by the students and development of the protests, and our conclusions about the analysis of the movement 'Do not close my school'.

\section{Protests as Wildfire Activities}

Social movements can be defined as a collective of people engaged in order to pursue a common objective [19]. They consist of activities, varying according to the needs of the participants involved and can have different forms, such as demonstrations, protests, parades or occupations. These forms of activities are not permanent: they emerge from a given need, may evolve and possibly fade away due to the constraints imposed by a certain system or institution.

In this study, we consider the activities involved in the movement 'Do not close my school' under the CulturalHistorical Activity Theory framework [24], [25], [26], which enables us to understand the implications of cultural and historical contexts for the development of the protests and its results. Given the frailty of such activities, the notion of wildfire activities, as proposed by Engeström [27] is suitable for our understanding of how the activities in the movement 'Do not close my school' developed. The author considers that the concept of wildfire activities demonstrates a potential for sustainability and expansion of the activities, which can also be applied to such a movement for three main reasons: '1) they offer little monetary reward, institutional support structures and legal protection. 2) they require excessive expenditures of time and energy, and 3) they carry a high risk of failure, trouble with authorities, or even physical harm' [27].

Wildfire activities pop up in unexpected space and time, and they are full of paradoxes: they are dispersed and distributed, yet well-coordinated and aware of the totality in each node; they use different communication technologies as mediational tools, but are not dependent on them; they occur both physically and virtually [27].

The movement 'Do not close my school' can be considered as a wildfire activity due to its organization by students, with little support from schools. Besides, it was a lengthy social movement, the schools were located in different cities, but connected though Facebook; they took place on the streets and online, and students were often threatened by the police and other authorities.

Considering that context of wildfire activities, the participants have the possibility of becoming successful for achieving their objectives in the protests when they develop agency. According to Giddens, agency is the capability one individual has to make a difference to a pre-existing condition or set of events [28]. However, being a deinstitutionalized movement, organized strictly by students, we understand that agency, as it was defined, is not enough for transforming a context such as the movement 'Do not close my school'.

Departing from the studies of Miettinen [29], [30], on collaborative agency, that is understood as the promotion of creative encounters in which participants engage towards a joint object, for solving a specific problem, we consider that changes are only possible when people work collaboratively, empowering each other in activities. Thus, we understand collaborative agency as a process in which participants become agents of an activity, by collaboratively constructing and envisioning new possibilities towards a joint object.

In our understanding, collaborative agency is possible when subjects experience creating, recreating and integrating themselves to their contexts, through cultural and historical experiences [31], considering the future as a solvable problem, and not as an inexorable and predetermined fact. By working collaboratively, the subjects are able to interfere in their reality, and not only to adapt themselves to it [32].

Therefore, by acting collaboratively students engaged in a movement of not accepting a given context, which would interfere in their well-being at their schools and eventually in their day to day lives, by getting organized to envision new possibilities for their present and then for their future.

\section{Research Setting}

\subsection{The Movement 'Do Not Close My School'}

In October 2015, the State Secretariat of Education of São 
Paulo announced a reorganization process of its educational system, in which ninety-four basic education schools would be closed and students and teachers would be reallocated to other schools [33]. The reorganization would demand students to walk more than five kilometres to reach their new schools, while by law students have the right to go to a school in a radius of one and a half kilometre from home. Besides, the way the reorganization was announced did not make it clear how students and teachers would be reallocated, and in the new schools classes would double the number of students and in some cases could reach from 85 to 95 students [34].

In order to protest against the Secretariat's decision, students initiated the movement 'Do not close my school', in which they occupied schools across the state of São Paulo, also creating pages on Facebook and organizing demonstrations on the streets in different cities of the state. It is important to highlight that there was no official support from teachers and school managers in the decision making, organization and in any activity of the movement itself.

First of all, the movement started in one school, in Diadema, a city in the outskirts of the metropolitan area of São Paulo, which was occupied by students on 9 October 2015, and another one in the city of São Paulo, occupied in the following day, on 10 October. Since the latter was located in a more central neighbourhood, the movement gained media attention. Ten days after the movement started, around one hundred schools were occupied, and by the end of November there were more than two hundred schools occupied by students in fifty-six different cities in the State of São Paulo [33].

In that period, students also protested on the streets of their cities, blocking important avenues by sitting on school desks, and military police force was used to contain the protesters, attacking the students with nightsticks and pepper spray. In some demonstrations, even the riot police was used against the students. Despite the excess of violence against the students, thirty three protesters were arrested during the movement period, and population considered the use of police force unnecessary, lowering the levels of perceived popularity of the state government [35].

In order to report the events in the movement 'Do not close my school' - either in the occupied schools or on the streets - students created Facebook pages or groups, in which they could share news, pictures or events taking place at the schools during the occupation. The 'Do not close my school' movement was supported by the local community as well as by some Brazilian famous artists, including actors, a popular MasterChef Brazil judge, who went to one of the occupied schools to cook for the students, and even singers, who performed at schools or composed songs for the movement. The most remarkable song had the following chorus: Nobody takes the throne of studying/Nobody is the owner of what life gives/And not even putting me in a jail/ Because classroom it what this jail is going to become.

After more than two months of occupations, demonstrations and online manifestations, the occupation of the schools ended by the end of December, after the governor of São Paulo announced the new plan about the school reorganization.

\subsection{Data Sources}

Data reported in this study were drawn from two sources: first, from fifty-six pages on Facebook related to the movement 'Do not close my school', and second, from 111 official pages of the State Schools, also on Facebook. All the information reported in this study was translated to English by the authors after the analysis of the original files in Portuguese. The posts considered for analysis on both types of pages - from the movement 'Do not close my school' and official school pages - were made from 9 October 2015, when the protest started, to 6 February 2016, when data was collected. All data was anonymized and no real names neither from schools nor from students - were used in this study.

\subsection{Procedures and Methods of Analysis}

In this study we adopted a mix-methods approach for analysing the data, combining multimodal analysis [36], [37], providing resources to analyse images, texts and other features of the pages, such as number of 'likes' or number of posts, and network analysis [10], [38], which helped us to understand the relations among the participants inside the pages of the movement 'Do not close my school'.

As a starting point for this study we used a list of every occupied school in the State of São Paulo, available at a newspaper from the main media [39]. First, the list was organized as a.xls file so we could perform a search on Facebook for all the schools listed. Then, we searched if the schools had an official page on Facebook, and subsequently if they had a page for the movement 'Do not close my school'. It is important to highlight that all pages found on Facebook are public, and their content is available to anyone with a Facebook account. In addition, any Facebook user can 'like' those pages and start following them up and receive updates on their newsfeed.

For searching the pages, different combinations of names were used, since the official names of the schools were hardly ever used, either for the official pages or the pages related to the movement 'Do not close my school'. In São Paulo, the state schools are all named beginning with 'State School', usually abbreviated S. S. [Escola Estadual - E. E. in Portuguese], followed by the name itself. For instance, for searching the pages of 'State School Professor Francisco Antonio Coelho, we used terms such as S. S. Prof Francisco Antonio Coelho or Occupy S. S. Prof Francisco, among others. The search for pages of all schools ended only after we tried a different number of possible name combinations for each school.

From more than two hundred occupied schools of the list, we identified fifty-six pages on Facebook related to the 'Do not close my school' movement. The pages were either named with the tag 'Do not close school X', with 'Occupy 
school Y' or 'Occupation school Z'. In addition, we found one 111 official pages of the schools. In this study, we consider the posts from 08 October 2015, when the first page related to the movement was created, to 06 February 2016, when data was gathered. The posts from the school official pages before that period were not considered in this study since they have no relation with the protests. We saved the pages on Facebook as a.pdf file, in which pictures and links were available for further access, and as an.xls file to be used with Node XL, a plugin for Microsoft Excel which enables us to perform network analysis (see https://nodexl.codeplex.com/ for more information on the software).

After finding the pages and classifying them as 'Official School Page' or 'Movement Page', we performed a multimodal analysis of the pages. First, we counted the number of 'likes', and the number of posts in each page. Second, we considered when the first and last post were made in each page. Third, we analysed the profile pictures and the cover photo of each page of the movement. Finally, we created a list with the topics of all the posts, so we could also analyse the content of the discussions involved in each group.

The last step of the analysis was to gather all.xls files from each page on Node XL and to perform a network analysis of the links shared among the pages on Facebook. For this step of analysis, we considered only the relations between schools and the links they shared as nodes in the network, not considering each participant of the network, for instance students or other people who liked the pages, as a separate node. From that analysis we could count the number of links and identify their sources. After that, the links were classified into main media and independent media. That analysis provided the understanding on how schools were connected among themselves and also by the content they shared in their pages.

\section{The Facebook Pages}

By using multimodal analysis of the pages, we identified some common characteristics among the pages of the movement. First, the profile pictures of the pages were mainly with a picture of the school building or with the school name. Those pictures demonstrated that, although the movement 'Do not close my school' was a student movement, they were connected to the school and that the school was the centre of attention. Second, the cover pictures showed statements such as: 'the school is ours', 'we do not want the reorganization' or 'occupy your school'. Third, there were only posts made by the pages' owner. Those cover pictures can be associated with the anti-reorganization tone of the protests. Figure 1 depicts one example of the Facebook pages of the movement. On a red background, we observe the statement \#occupy your school [\#ocupe sua escola] as a cover picture, and four small pictures of the school as profile picture.

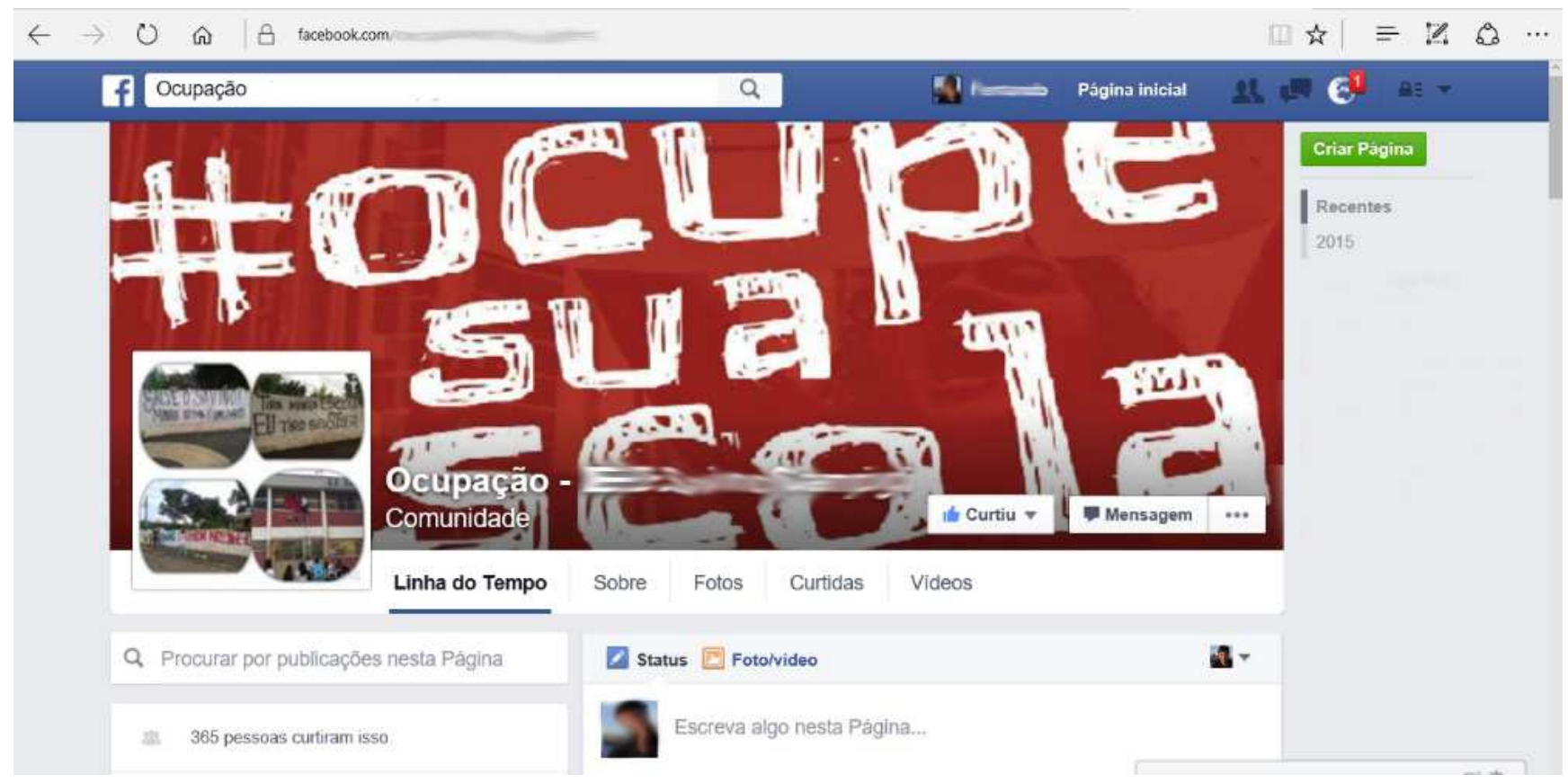

Figure 1. Example of a Facebook page of the movement 'Do not close my school'. The name of the school and other personal information in the page were blurred.

Although the pages had a similar visual aspect, the number of posts and followers varied from page to page. Based on the Excel files of each group, we identified that the number of posts varied from six to $304(n=5,390$, mean $=96)$, while the number of followers varied from sixty-one to 10,290
$($ mean $=1,102)$, with a total number of 61,732 people connected to the Facebook pages. The Facebook page of the school with only six posts and 61 followers was created by the students three days before the movement ended, and the school was located in a small town in the countryside. On the 
other hand, the school page with 10,290 followers was created in the second day of the movement and is located in a prestigious neighbourhood in the city of São Paulo. In addition, it was the page with the highest number of posts $(n=304)$.

The analysis of the posts also demonstrated how the content shared by the groups of students reached people who were not following the pages of the movement. First, the 'like' button on Facebook was used 127,373 by the followers of the groups, and the number of co-likers was 46,191; second, the number of comments on the posts was 182,798 and the number of co-comments was 1,049. The co-likers and co-commenters are people who see what a friend on Facebook liked or commented but are not part or followers of a group. However, they are also able to like or comment that given post.

The posts on the pages on Facebook revealed that students were more likely to share links from the independent media than from the main media. In total, there were 237 links, from ninety-four sites of independent media, and eighty-one links from the main media, from sixteen different sources. However, when students shared links from the main media, they were more likely to comment them in a negative way, sometimes with comments such as 'they are not telling the truth' or 'see how they (the newspaper) treat us!', while when sharing posts from the independent media they seemed to be more in accordance with them.

Although we could find more than one hundred official pages from the schools, only five of them shared pictures, links or other information about the movement 'Do not close my school', in the same way the movement pages would do. In other nineteen official pages from the schools we could only observe posts with messages such as 'The school is occupied' or 'We will inform parents about the school calendar after the occupation ends'. This again reinforces how students were responsible for the movement, and that no direct support from the schools were given.

Findings also pointed out that schools were little related to each other online, and there were only sixteen cases in which the page of one school directly mentioned pages of other schools. However, they were strongly connected via the links they shared on their pages. The network analysis of the pages depicted on Figure 2 pictures how schools were connected. While we can observe three big blue diamonds for the mass media, there are two big ones and nine a little bit smaller for the for the independent media, occupying a central position in the network, which demonstrates the influence of the independent media for such social movements.

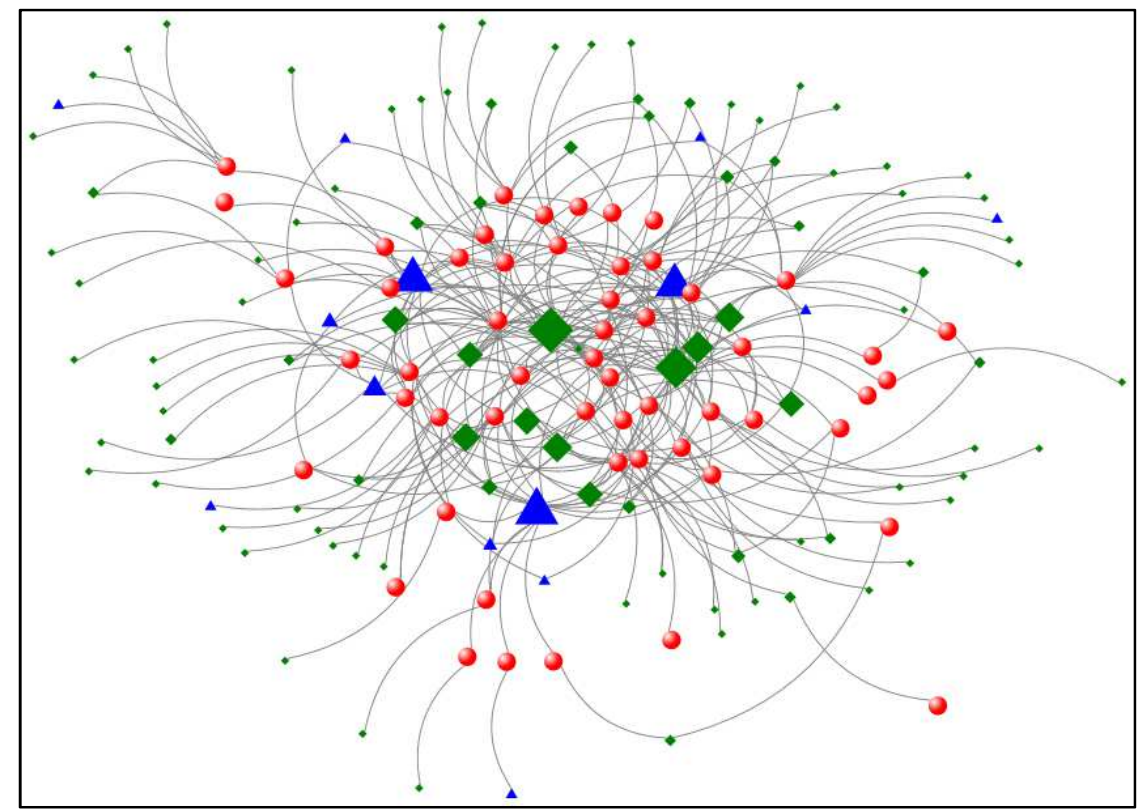

Figure 2. Network analysis of the links shared on the movement pages. The spheres represent the schools, the triangles are the main media, and the diamonds represent the independent media. The alternative media occupies a more central position in relation to the main media.

Thus, the news and links from the main media shared on the school pages were usually used by the students to make their followers aware of the different realities shown by the media and what they really perceived. However, the news and links shared from the independent media were more likely to portrait the reality the students were facing, what justifies the high number of big green diamonds connections among the schools.

After the movement 'Do not close my school' ended, some students continued to use their pages of protest on Facebook for other activities, including events disclosure and even for other social movements. From the fifty-six pages identified in this study, thirty had posts after 01 January 2016, either related to the success of the movement 'Do not close my school' or to the new activities they were used for.

\section{Discussing the Movement 'Do Not Close My School'}

As mentioned previously in this article, the movement 'Do 
not close my school' started in October 2015 and ceased in December 2015. During the two months of school occupations and demonstrations on the streets of important cities of the State of São Paulo, students faced tension with authorities in order to fight against the government decision.

Considering the number of people connected to Facebook in Brazil - more than 90 million active users [40] - when a person who follows a fan page on Facebook 'likes' or 'comments' a link, all the friends from that person can see what they liked or commented on their newsfeed on Facebook, even if they had not followed the page of the movement. Thus, the protestors could reach people from outside their own communities by sharing their own news about the protests, no matter what the main media broadcasted about the movement, showing the importance of social networking sites such as Facebook for this kind of protest.

The number of links shared on the movement pages also highlighted how students could see the importance of the independent media. From every four links shared on the movement pages, three were from the independent media. In the same direction, we relate to Engeström [27] to point out that the use of Facebook as a mediational communicative tool offers more accurate information than the mass media. In addition, Facebook pages enabled the connection between online and physical protests.

Although the relation among the pages of the movement on Facebook was not so tight, the connection could be seen from the links they shared on the pages. The network analysis represented on Figure 2 recalls a paradox of the wildfire activities, as proposed by Engeström [27]: they are dispersed and distributed, since some of the schools occupy a more peripheral position in the network; but present coordination and awareness of the totality in each node, which can be seen in the connections among different types of media and schools.

Besides, the Facebook pages also mobilized different stakeholders via media and schools to engage into the protests. Such digital creative encounter can be understood as a first sight of collaborative agency towards the joint object of not closing the schools. By acting collaboratively, the subjects were potentially stronger to interfere in the reality, instead of simply accepting the decisions and adapting themselves to the context [32].

After two weeks of occupations, the State Secretary of Education proposed to postpone the educational system reorganization. However, in order to postpone it, students were required to abandon the occupations and stop the demonstrations. Students decided it was not the best moment to interrupt the protests, since the Secretary of Education did not present any concrete plan for the reorganization. Subsequently, during the first week of December, the Governor of São Paulo announced publicly that the reorganization of the educational system would be cancelled, and they would start planning how the new reorganization would be. This caused tension in the government, which made the Secretary of Education to resign. Even after the announcement and the secretary resignation, students kept the schools occupied.

In both cases, the historical experiences, as suggested by Freire [31], [41], related to previous educational manifestations in Brazil played an important role in the relation between the ones who have power and take decisions and the ones who are directly affected by the decisions without previous negotiation or consultation. By collaboratively empowering themselves, students could break the boundaries between oppressor and oppressed demanding an official decision that would not harm their day to day lives. The occupations of the schools ended only after the governor officially assured that no reorganization would take place and that schools would not be closed.

\section{After 'Do Not Close My School', More Activities, More Protests}

After the end of the movement 'Do not close my school', which resulted on keeping their schools opened, some groups of students continued using their groups on Facebook for different purposes. They used the pages, for example, to organize extra-curricular activities, or to share the events taking place in their schools. From the fifty-six pages related to the movement 'Do not close my school', thirty pages were actively in use after 1 January 2016. The pages on Facebook were also used for engaging in other protests.

Since most of the schools to be closed were located in the city of São Paulo and nearby cities in the metropolitan area, the students from the movement 'Do not close my school' started protesting against the rise of the public transport fare. The groups started collaborating with a pre-existing group, named 'Movement Free Pass' [Movimento Passe Livre], which tries to obtain the right for free public transport for all citizens of São Paulo. The pages on Facebook were used in the same way they were used during the occupations: they reported what happened during the demonstrations and what the media was showing.

The new demonstrations pointed a change in the object demonstrated by the expansion of the activity, which was initially intended for protesting against the closure of the schools, to other contexts. That expansion can be understood as another sight of collaborative agency: the empowerment students gained in the movement 'Do not close my school' provided them more strength and organization to fight for the free pass in the public transportation in the city of São Paulo.

As a consequence of such manifestations, the mayor of the city of São Paulo granted the right to free transport to all students in the city, either from public or private schools. The free pass was achieved in less than two weeks of protests and demonstrations, with no use of military police or other kind of violence against the protestors. This result demonstrates how the agency of the students was important for protesting and obtaining good results after the manifestations.

A new series of manifestations has been boosted since students started having problems with school food, which 
is provided by the State with no costs for the students. A large scheme of bribery was found out by the Public Ministry and has been investigated since then, creating new motives to keep students active on Facebook pages and on the streets.

\section{Conclusions}

This article described an exploratory study on how students from the public educational system of São Paulo, Brazil, protested against the closure of ninety-four schools from the State Educational System. The movement named 'Do not close my school' was a combination of an occupytype protest, and demonstrations on the streets, organized and spread via Facebook pages.

We consider the protests as a form of wildfire activities bearing three reasons in mind: 1) students do not have any monetary reward or support, neither institutional support nor legal protection; 2) students also spent time and energy in the movement since they spent nights and weekends at school; and 3) students were not sure about the final decision of the government, though they persisted in the movement many times being threatened by the police inside and outside schools.

Throughout this exploratory study we identified two cases in which collaborative agency emerged: first, when students were engaged and working collaboratively in order to avoid the closure of the schools, and second, when the students expanded the object of the protests to another context, so they could then claim the right for a free pass in public transport. By using Facebook as a mediational communicative tool, students could coordinate their actions, either during the occupations or during the demonstrations in the different cities.

We conclude that the success of such manifestations was only possible due to the big number of schools involved, and due to the easiness of sharing information through a social networking site. Although nearly one fourth of the 200 occupied schools were active on Facebook, the pressure put on the authorities by the students, using a combination of occupy protest and demonstrations, was a nice opportunity to demonstrate how the collaborative agentive aspect of the protests can be seen as a powerful tool for obtaining significant results in social movements.

\section{References}

[1] S. Brunsting and T. Postmes, "Social movement participation in the digital age - Predicting offline and online collective action," Small Gr. Res., vol. 33, no. 5, pp. 525-554, 2002.

[2] S. González-Bailón, J. Borge-Holthoefer, and Y. Moreno, "Broadcasters and Hidden Influentials in Online Protest Diffusion," Am. Behav. Sci., vol. 57, no. 7, p. 943, 2013.

[3] J.-L. Micó and A. Casero-Ripollés, "Political activism online: organization and media relations in the case of $15 \mathrm{M}$ in Spain," Information, Commun. Soc., vol. 17, no. 7, pp. 858-871, 2014.
[4] M. F. Lemos and F. Cunha Jr, "Facebook in Brazilian schools: mobilizing to fight back," Mind, Cult. Act., 2017.

[5] D. Mercea, "Probing the implications of Facebook use for the organizational form of social movement organizations," Inf. Commun. Soc., vol. 16, no. 8, pp. 1306-1327, 2013.

[6] A. Vromen, M. A. Xenos, and B. Loader, "Young people, social media and connective action: from organisational maintenance to everyday political talk," J. Youth Stud., vol. 18, no. 1, pp. 80-100, 2015.

[7] F. Frenzel, A. Feigenbaum, and P. McCurdy, "Protest camps: an emerging field of social movement research," Sociol. Rev., vol. 62 , no. 3 , pp. 457-474, 2014.

[8] A. Velasquez and R. Larose, "Youth collective activism through social media: The role of collective efficacy," New Media Soc., vol. 17, no. 6, pp. 899-918, 2015.

[9] L. Yates, "Everyday politics, social practices and movement networks: daily life in Barcelona's social centres," $B r . J$. Sociol., vol. 66, no. 2, pp. 236-258, 2015.

[10] F. Bailo, "Mapping online political talks through network analysis: a case study of the website of Italy's Five Star Movement," Policy Stud., vol. 36, no. 6, pp. 550-572, 2015.

[11] C. Guzman-Concha, "The Students' Rebellion in Chile: Occupy Protest or Classic Social Movement?," Soc. Mov. Stud., pp. 1-8, 2012.

[12] B. N. Jaworsky, "Mobilising for Immigrant Rights Online: Performing 'American' National Identity through Symbols of Civic-Economic Participation,” J. Intercult. Stud., vol. 36, no. 5, pp. 579-599, 2015.

[13] S. Harlow, "Social media and social movements: Facebook and an online Guatemalan justice movement that moved offline," New Media Soc., vol. 14, no. 2, pp. 225-243, 2012.

[14] J. Pickerill and J. Krinsky, "Why Does Occupy Matter?," Soc. Mov. Stud., vol. 11, no. 3-4, pp. 279-287, 2012.

[15] A. Adi, "Occupy PR: An analysis of online media communications of Occupy Wall Street and Occupy London," Public Relat. Rev., vol. 41, no. 4, p. 508, 2015.

[16] F. R. da Cunha Jr., C. van Kruistum, and B. van Oers, "Teachers and Facebook: using online groups to improve students' communication and engagement in education," Commun. Teach., vol. 30, no. 4, pp. 228-241, 2016.

[17] U. Dolata and J.-F. Schrape, "Masses, Crowds, Communities, Movements: Collective Action in the Internet Age," Soc. Mov. Stud., vol. 15, no. 1, pp. 1-18, 2016.

[18] F. Rojas, "Social Movement Tactics, Organizational Change and the Spread of African-American Studies," Soc. Forces, vol. 84, no. 4, pp. 2147-2166, 2006.

[19] J. D. Borrero, S. Y. Yousafzai, U. Javed, and K. L. Page, "Expressive participation in Internet social movements: Testing the moderating effect of technology readiness and sex on student SNS use," Comput. Human Behav., vol. 30, pp. 3949, 2013.

[20] M. Foucault, "The subject and Power," Crit. Inq., vol. 8, no. 4, pp. 777-795, 1982.

[21] M. Castells, Networks of Outrage and Hope: Social Movements in the Internet Age. Cambridge, UK: Polity Press, 2012. 
[22] A. Maireder and C. Schwarzenegger, "A movement of connected individuals: Social media in the Austrian student protests 2009," Information, Commun. Soc., vol. 15, no. 2, pp. $171-195,2012$.

[23] S. Costanza-Chock, "Mic Check! Media Cultures and the Occupy Movement," Soc. Mov. Stud., pp. 1-11, 2012.

[24] Y. Engeström, Learning by expanding. An activity theoretical approach to developmental research, 1st ed. Helsinki: Orienta Konsultit, 1987.

[25] A. N. Leontiev, Activity, consciousness and personality. Englewood Cliffs, NJ: Prentice Hall, 1978.

[26] L. S. Vygotsky, The Collected Works of L. S. Vygotsky, 1st ed., vol. 4. New York and London: Plenum Press, 1987.

[27] Y. Engeström, "Wildfire activities: new patterns of mobility and learning," J. Mob. Blended Learn., vol. 1, no. 2, p. 18, 2009.

[28] A. Giddens, The constitution of society. Outline of the theory of structuration. Los Angeles: University of California Press, 1986.

[29] R. Miettinen, "Creative encounters and collaborative agency in science, technology and innovation," in Handbook of research on creativity, K. Thomas and J. Chan, Eds. Edward Elgar Publishing, 2013, pp. 435-449.

[30] R. Miettinen, "Creative encounters and the emergence of object-oriented collaborative agency," in European Group of Organizational Studies, 2010.

[31] P. Freire, Educação como prática da liberdade [Education as liberty practice]. Rio de Janeiro: Paz e Terra, 1967.
[32] P. Freire, Pedagogia da Autonomia [Pedagogy of autonomy], 49 ${ }^{\mathrm{a}}$. Rio de Janeiro: Paz \& Terra, 2014.

[33] L. Deus, "Entenda a evolução das ocupações de escolas em São Paulo [Understanding the evolution of school occupation in São Paulo," Revista Educação, Editora Segmento, São Paulo, Mar-2015.

[34] V. Barbara, "Another defeat for Brazil's Kids," The New York Times, The New York Times Company, New York, 2015.

[35] R. Azevedo, "Em meio a invasões de escolas, promovidas por PT e outros, cai popularidade de Alkmin," Veja, vol. 2015, Abril, São Paulo, Mar-2015.

[36] C. J. Forceville, "Book review: Multimodality: A Social Semiotic Approach to Contemporary Communication," J. Pragmat., vol. 43, no. 14, pp. 3624-3626, 2011.

[37] G. Kress, Literacy in the New Media Age. London: Routledge, 2003.

[38] J. van Dijk, The network society, 2nd ed. London: SAGE Publications, 2006.

[39] Globo, "Veja a lista das escolas ocupadas no estado de São Paulo [Check the list of occupied schools in the state of São Paulo]," G1 São Paulo, Globo, São Paulo NV - Daily, Mar2015.

[40] Facebook, "45\% da população brasileira acessa o Facebook mensalmente $[45 \%$ of Brazilians access Facebook every month]," vol. 2016. Facebook, 2015.

[41] P. Freire, Pedagogy of the oppressed. New York: Herder and Herder, 1970. 